\title{
Absorption characteristics of compounds with different molecular weights after application to the unilateral kidney surface in rats
}

\author{
Koyo Nishida ${ }^{\mathrm{a}, *}$, Naoki Tomiyama ${ }^{\mathrm{a}}$, Takahiro Mukai ${ }^{\mathrm{a}}$, Mikiro Nakashima ${ }^{\mathrm{b}}$, Hitoshi Sasaki ${ }^{\mathrm{b}}$, \\ Junzo Nakamura ${ }^{\mathrm{a}}$
}

${ }^{a}$ Department of Clinical Pharmacy, Graduate School of Biomedical Sciences, Nagasaki University, 1-14 Bunkyo-machi, Nagasaki 852-8521, Japan

${ }^{b}$ Department of Hospital Pharmacy, Nagasaki University School of Medicine, 1-7-1 Sakamoto, Nagasaki 852-8501, Japan

\footnotetext{
* Corresponding author. Department of Clinical Pharmacy, Graduate School of Biomedical Sciences, Nagasaki University, 1-14 Bunkyo-machi, Nagasaki 852-8521, Japan. Tel.: +8195-819-2454. Fax: +81-95-819-2897.

E-mail address: koyo-n@net.nagasaki-u.ac.jp (K. Nishida).
}

European Journal of Pharmaceutics and Biopharmaceutics, 58 (3), 705-711, 2004 


\begin{abstract}
The aim of the present study is to clarify the absorption mechanism of a drug from the kidney surface membrane in rats. We studied the absorption characteristics of phenolsulfonphthalein (PSP) and other compounds with different molecular weights after their application to the rat kidney surface in vivo, employing a cylindrical diffusion cell (i.d. 6 $\mathrm{mm}$, area $0.28 \mathrm{~cm}^{2}$ ). The time course of free PSP amounts remaining in the diffusion cell obeyed first-order kinetics at a dose of $1 \mathrm{mg}$, and its rate constant $\mathrm{k}_{\mathrm{a}}$ was calculated to be $0.0137 \mathrm{~min}^{-1}$. Absorption ratios of PSP in $4 \mathrm{~h}$ were calculated from the amount recovered from the diffusion cell to be $91.4,96.4$ and $97.7 \%$ at doses of $0.5,1$ and $1.5 \mathrm{mg}$, respectively. The area under the curve for the plasma concentration profile of free PSP was proportional to the application dose. It is thus suggested that the absorption process of PSP from the rat kidney surface does not approach saturation at a dose of $1.5 \mathrm{mg}$. Also, no significant difference was seen in the $k_{a}$ values within the dose range of 0.5 - $1.5 \mathrm{mg}$, which were estimated by curve-fitting the plasma concentration profiles of free PSP in a two-compartment model with first-order absorption. Furthermore, we examined the importance of molecular weight on the absorption from the kidney surface using fluorescein isothiocyanate-dextrans (FDs) with molecular weights of 4,400 (FD-4), 11,000 (FD-10), 40,500 (FD-40) or 69,000 (FD-70), including the organic anions bromphenol blue and bromosulfonphthalein. The absorption ratios of FDs from the rat kidney surface in $6 \mathrm{~h}$ decreased with an increase in the molecular weight (76.1 \% for FD-4, $54.4 \%$ for FD-10, $11.5 \%$ for FD-40 and $3.9 \%$ for FD70). A linear relationship was observed between the $k_{a}$ and the reciprocal value with the square root of the molecular weight of these compounds. The limit of absorption from the rat kidney surface was extrapolated to be at a molecular weight of approximately 130,000. Keywords: Absorption; Kidney surface; Rat; Molecular weight; Pharmacokinetics; Targeting
\end{abstract}




\section{Introduction}

The kidney plays such an important role in drug disposition in the body that there is an increasing interest to improve therapy for kidney diseases. It is desired that an administered drug should be distributed largely into the target site of the kidney, proposing to treat kidney diseases, e.g. a localized tumor. The renal arterial administration of poly (stylene-co-maleic acid)-conjugated neocarzinostatin (SMANCS)/lipiodol [1,2] or microcapsule chemoembolization [3-6] has been studied to target anticancer drugs at the unilateral kidney to enhance their efficacy and to reduce their toxicities.

In general, normal routes of drug administration have difficulties in reaching local sites of action in the unilateral kidney, because of high blood circulation rates and microvascular permeability in the kidney. Although the direct way is supposed to be a useful method, the direct injection route into the kidney is not suitable for targeted site-selective drug delivery. This is because directly injected drugs are rapidly cleared from the injected site with high blood flow, followed by drainage into the systemic circulation. In contrast, a kidney surface application does not stress the kidney with no injury, and continuous catheter administration may be capable of long-term application. In a previous study [7] we elucidated the kidney- and site-selective delivery of the anticancer drug 5-fluorouracil (5-FU), utilizing absorption from the kidney surface in the rats. At first, an experimental system employing a cylindrical diffusion cell attached to the unilateral kidney surface was established. After applying 5-FU to the rat kidney surface, the concentration of 5-FU in the applied kidney was significantly higher than concentrations in the non-applied kidney and other tissues. However, the absorption mechanism of a drug from the kidney surface remains to be examined.

The main purpose of the present study is to obtain basic information concerning the absorption mechanism from the kidney surface membrane. Kinetic analysis of drug 
absorption from the kidney surface is of particular interest physiologically and important for clinical use of this administration method. First, we analyzed absorption characteristics pharmacokinetically such as dose dependency in phenolsulfonphthalein (PSP) absorption from the kidney surface because its absorption characteristics from the rat liver surface had been fully investigated [8-11].

In addition, we selected four types of fluorescein isothiocyanate-dextrans (FDs) with different molecular weights as model macromolecules and the organic anions bromphenol blue (BPB) and bromosulfonphthalein (BSP), and studied their in vivo pharmacokinetics after application to the rat kidney surface. There are some reports concerning the molecular weight dependence of peritoneal transport [12-17] and the accumulation of macromolecules in several organs after intraperitoneal (i.p.) administration [18,19]. However, the absorption characteristics of macromolecules across the kidney surface membrane is still unknown.

\section{Materials and methods}

\subsection{Materials}

PSP and BPB were purchased from Nacalai Tesque, Inc. (Kyoto, Japan). $\quad$ BSP and FDs with average molecular weights of 4,400 (FD-4), 11,000 (FD-10), 40,500 (FD-40) or 69,000 (FD-70) were obtained from Sigma Chemical Co. (St. Louis, MO, USA). All other chemicals were of reagent grade products.

\subsection{Animal experiment}

All animal procedures in the present study conformed to the Guideline for Animal Experimentation in Nagasaki University.

Male Wistar rats (220-290 g) were anesthetized with sodium pentobarbital (50 mg/kg, i.p.) and the left femoral artery was cannulated with a polyethylene tube (i.d. $0.5 \mathrm{~mm}$, o.d. 0.8 
mm, Dural Plastics, Dural, Australia). After the middle abdomen was cut open about $3 \mathrm{~cm}$, the common bile duct was cannulated with a polyethylene tube (i.d. $0.28 \mathrm{~mm}$, o.d. $0.61 \mathrm{~mm}$, Becton Dickinson \& Co., Parsippany, NJ, USA). The body temperature of rats was kept at $37^{\circ} \mathrm{C}$ by a heat lamp during the experiment. The drug solution was prepared in an isotonic phosphate buffer ( $\mathrm{pH} 7.4$ ), and administered as follows.

Application to rat kidney surface: A cylindrical diffusion cell (i.d. $6 \mathrm{~mm}$, area $0.28 \mathrm{~cm}^{2}$ ) was attached to the rat left kidney surface with adhesive chemical Aron Alpha (Sankyo Co. Ltd., Tokyo, Japan). The drug solution $(0.05 \mathrm{ml})$ was added to the diffusion cell directly. The top of the diffusion cell was sealed by a piece of aluminum foil to prevent evaporation of the applied solution.

I.v. administration: The drug solution $(0.1 \mathrm{ml})$ was injected into the jugular vein.

After application of the drug solution a $200 \mu$ l blood sample was collected at selected times from the heparinized cannula inserted into the femoral artery over 4 or $6 \mathrm{~h}$ and centrifuged at 15,000 rpm for 5 min. Bile samples were collected at appropriate time intervals for 4 or $6 \mathrm{~h}$. The urine was collected from the bladder directly by a syringe and the solution remaining in the diffusion cell was withdrawn at 4 or $6 \mathrm{~h}$ after the application.

\subsection{Analytical methods}

The concentrations of compounds in the plasma, bile, urine, and the solution remaining in the diffusion cell were determined as follows.

PSP: The concentration of free PSP was determined spectrophotometrically at $560 \mathrm{~nm}$ after dilution with $1 \mathrm{M} \mathrm{NaOH}$ solution. The total concentration of free PSP and its metabolite was measured in the same manner after they were subjected to acid hydrolysis (1 $\mathrm{M} \mathrm{HCl}$ at $100{ }^{\circ} \mathrm{C}$ for $30 \mathrm{~min}$ ) [20]. The concentration of PSP metabolite was estimated from the difference between these values.

BPB: The concentration of BPB was determined spectrophotometrically at $600 \mathrm{~nm}$ after 
dilution with an isotonic phosphate buffer (pH 7.4) [21].

BSP: The concentration of BSP was determined spectrophotometrically at $580 \mathrm{~nm}$ after dilution with $0.1 \mathrm{M} \mathrm{NaOH}$ solution [22].

FDs: The concentrations of FDs as fluorescence in the plasma, bile, urine and solution remaining in the diffusion cell were measured by a spectrophotofluorometer at excitation and emission wavelengths of 489 and $515 \mathrm{~nm}$, respectively.

\subsection{Calculation of pharmacokinetic parameters}

The plasma concentration profile of free PSP was analyzed based on the statistical moment theory. Moment parameters for the plasma concentration profile of free PSP $\left(\mathrm{AUC}_{\mathrm{p}}, \mathrm{MRT}_{\mathrm{p}}\right)$ are calculated by numeral integration using a linear trapezoidal formula and extrapolation to infinite time based on a monoexponential equation [23].

\subsection{Compartment model analysis}

First, the plasma concentration $\left(\mathrm{C}_{\mathrm{p}}\right)$ profiles of free PSP at doses of 0.5, 1 and $1.5 \mathrm{mg}$ after i.v. administration into rats were fitted to the biexponential equation described as follows, by the nonlinear least-squares method [24].

$$
C_{p}=\frac{D\left(\alpha-k_{21}\right)}{V_{c}(\alpha-\beta)} e^{-\alpha \cdot t}+\frac{D\left(k_{21}-\beta\right)}{V_{c}(\alpha-\beta)} e^{-\beta \cdot t}
$$

Hybrid parameters $\alpha$ and $\beta$ are defined as $\alpha+\beta=\mathrm{k}_{12}+\mathrm{k}_{21}+\mathrm{k}_{\mathrm{el}}$ and $\alpha \cdot \beta=\mathrm{k}_{21} \cdot \mathrm{k}_{\mathrm{el}} . \quad \mathrm{V}_{\mathrm{c}}$ is the volume of the central compartment. $\quad \mathrm{k}_{\mathrm{el}}$ is the first-order elimination rate constant from the central compartment. $\quad \mathrm{k}_{12}$ and $\mathrm{k}_{21}$ are the first-order transfer rate constants between the central and peripheral compartment. These parameters were substituted into the following equation for the plasma concentration after application of PSP to the rat kidney surface.

Next, in the same way, the plasma concentration profile of free PSP after application to the rat kidney surface was fitted in a two-compartment model with first-order absorption by the nonlinear least-squares method [24]. In this model, the equation for plasma concentration 
of free PSP is given by the following equation.

$$
C_{p}=\frac{F \cdot D \cdot k_{a}}{V_{c}}\left\{\frac{k_{21}-k_{a}}{\left(\beta-k_{a}\right)\left(\alpha-k_{a}\right)} e^{-k_{a} \cdot t}+\frac{k_{21}-\alpha}{(\beta-\alpha)\left(k_{a}-\alpha\right)} e^{-\alpha \cdot t}+\frac{k_{21}-\beta}{(\alpha-\beta)\left(k_{a}-\beta\right)} e^{-\beta \cdot t}\right\}
$$

$\mathrm{k}_{\mathrm{a}}$ is the first-order absorption rate constant for PSP absorption into the blood stream from the rat kidney surface. $\quad$ F is the availability of PSP after application to the rat kidney surface.

\section{Results and Discussion}

\subsection{Absorption of PSP after application to the rat kidney surface}

To assess the absorption characteristics from the rat kidney surface membrane, we first studied the time course of the free PSP amount remaining in the diffusion cell after application to the rat kidney surface at a dose of $1 \mathrm{mg}$. The extent of PSP absorption in $4 \mathrm{~h}$ was calculated as $96.4 \%$ by the dose and the amount recovered from the diffusion cell. As shown in Fig. 1, the semi-log plot of free PSP amount remaining in the diffusion cell made a straight line (correlation coefficient: $\mathrm{r}^{2}=0.98$ ), indicating that PSP absorption from the rat kidney surface proceeds via first-order. Its first-order absorption rate constant $\mathrm{k}_{\mathrm{a}}$ was calculated to be $0.0137 \mathrm{~min}^{-1}$. Also, this result supports the employment of the twocompartment model incorporating first-order absorption to describe the plasma concentration profile of free PSP after application to the rat kidney surface.

\subsection{Dose dependency on PSP absorption after application to the rat kidney surface}

Fig. 2 shows the plasma concentration profiles of free PSP after application to the rat kidney surface at doses of 0.5, 1 and $1.5 \mathrm{mg}$. At every dose, the plasma concentration of free PSP reached a maximum, followed by a gradual disappearance. Table 1 lists the recovery of free PSP and its metabolite (\% of dose) in the bile, urine and diffusion cell at $4 \mathrm{~h}$ 
after i.v. administration or application to the kidney surface in rats at doses of $0.5,1$ and 1.5 mg. Absorption ratios of PSP in $4 \mathrm{~h}$ calculated from the free PSP amount remaining in the diffusion cell were $91.4,96.4$ and $97.7 \%$ at doses of $0.5,1$ and $1.5 \mathrm{mg}$, respectively, indicating no saturation of PSP absorption from the rat kidney surface membrane within the dose range used.

As shown in Table 1, free PSP and its metabolite were excreted into both bile and urine on each administration route. The urinary and biliary recoveries of free PSP and its metabolite after application to the rat kidney surface were broadly similar to those after i.v. administration. It is supposed that the drug metabolism and excretion processes of a drug are not affected by its application to the kidney surface.

Moment parameters are free from the complexities of a pharmacokinetic model, and thus $\mathrm{AUC}_{\mathrm{p}}$ and $\mathrm{MRT}_{\mathrm{p}}$ can be appropriate parameters to evaluate roughly the drug absorption rate and extent from the kidney surface. Table 2 summarizes the moment parameters of free PSP after application to the rat kidney surface at doses of 0.5, 1 and $1.5 \mathrm{mg}$. No significant difference was seen in the $\mathrm{AUC}_{\mathrm{p}} /$ dose value among the three doses, indicating linearity of PSP absorption from the rat kidney surface membrane. Also, $\mathrm{MRT}_{\mathrm{p}}$ values were almost the same among the three doses. The MRT palues of free PSP after its application to the rat kidney surface were fairly larger than those after i.v. administration. The prolonged $\mathrm{MRT}_{\mathrm{p}}$ value is a reflection of the time required for absorption process across the kidney surface. The mean absorption time (MAT) of PSP across the rat kidney surface was calculated by subtracting the $\mathrm{MRT}_{\mathrm{p}}(124 \mathrm{~min})$ after i.v. administration from the $\mathrm{MRT}_{\mathrm{p}}$ after application to the rat kidney surface, as listed in Table 2.

\subsection{Pharmacokinetic analysis of PSP absorption after application to the rat kidney surface}

We confirmed that the in vivo disposition after i.v. administration of PSP obeyed the two- 
compartment model, and the pharmacokinetic parameters were already obtained. The plasma concentration profile of free PSP after its application to the rat kidney surface was fitted into a two-compartment model with first-order absorption. The $\mathrm{k}_{\mathrm{a}}$ values obtained by curve-fitting the plasma concentration profile of free PSP were calculated to be 0.0128 , 0.0139 and $0.0141 \mathrm{~min}^{-1}$ at doses of $0.5,1$ and $1.5 \mathrm{mg}$, respectively. Fig. 2 also shows the fitted curves for the plasma concentration of free PSP after its application to the rat kidney surface at doses of $0.5,1$ and $1.5 \mathrm{mg}$, which had been reconstructed employing the estimated pharmacokinetic parameters. In general, agreement was observed between the fitted lines and experimentally observed data at every dose as shown in Fig. 2.

The obtained $\mathrm{k}_{\mathrm{a}}$ of PSP $\left(0.0139 \mathrm{~min}^{-1}\right)$ at a dose of $1 \mathrm{mg}$ obtained by curve-fitting (Fig. 2) correlated closely with the value determined by an elimination profile of free PSP from the diffusion cell (0.0137 $\mathrm{min}^{-1}$, Fig. 1), suggesting the validity of the pharmacokinetic model. In addition, no significant difference was seen in the $\mathrm{k}_{\mathrm{a}}$ values at doses of $0.5,1$ and $1.5 \mathrm{mg}$, supporting the linearity of PSP absorption from the rat kidney surface membrane.

Accordingly, it is suggested that specialized transport processes such as active transport might not exist in the PSP absorption from the rat kidney surface membrane. Thus, a simple passive diffusion is considered to play an important role in the PSP absorption from the kidney surface. In the future, several factors influencing the drug absorption from the kidney surface should be clarified for practical clinical use.

\subsection{Absorption of compounds with different molecular weights after application to the rat} kidney surface

Since molecular weight seems to play an important role in drug absorption from the kidney surface membrane, the absorption mechanism of macromolecules itself needs to be carefully examined for clinical application of macromolecules such as biologically active 
peptides. We selected four different FDs, because dextrans are fairly resistant to metabolic degradation and their in vivo fate has been characterized fully in rats [25-28].

Fig. 3 illustrates the plasma concentration profiles of FDs with different molecular weights after application to the rat kidney surface at a dose of $1 \mathrm{mg}$. All FDs were absorbed from the kidney surface, followed by progressive appearances in the plasma. With regard to FD-40 and FD-70, their plasma levels either plateaued or continued to rise until $6 \mathrm{~h}$ after dosing, compared to FD-4 and FD-10.

Table 3 lists the recovery of FDs in 6 h together with three different organic anions (PSP, $\mathrm{BPB}, \mathrm{BSP}$ ) in the diffusion cell, bile and urine after application to the rat kidney surface at a dose of $1 \mathrm{mg}$. The absorption ratios of FDs from the rat kidney surface in $6 \mathrm{~h}$ were calculated from the amount recovered from the diffusion cell as 76.1 \% for FD-4, 54.4 \% for FD-10, $11.5 \%$ for FD-40 and $3.9 \%$ for FD-70. An increase in the molecular weight of FDs resulted in a decrease in the absorption rate from the rat kidney surface.

Fig. 4 summarizes the $\mathrm{k}_{\mathrm{a}}$ of PSP, BPB, BSP and FDs (FD-4, FD-10, FD-40, FD-70) after application to the rat kidney surface. The calculated $k_{a}$ of these compounds decreased with the increase in molecular weight as shown in Fig. 4, indicating that the drug absorption from the kidney surface was affected greatly by the molecular weight.

\subsection{Relationship between molecular weights and absorption rate of compounds after application to the rat kidney surface}

We compared the absorption rates of several compounds having different molecular weights to predict the absorption rate from the kidney surface by physicochemical characteristics such as molecular weight. The following equation has been proposed with respect to the drug absorption from the stomach and small intestine via passive diffusion $[29,30]$ on the basis of the principle that the diffusibility of a substance in uniform solutions is 
approximately inversely proportional to the square root of the molecular weight of the drug $(\sqrt{\mathrm{Mw}})$.

$\frac{1}{\sqrt{\mathrm{Mw}} \cdot \mathrm{k}_{\mathrm{a}}}=\mathrm{A}+\frac{\mathrm{B}}{\mathrm{P}_{\mathrm{a}}}$

Where $\mathrm{P}_{\mathrm{a}}$ represents the partition coefficient and constants $\mathrm{A}$ and $\mathrm{B}$ are a correction factor to $\mathrm{P}_{\mathrm{a}}$ and a constant for diffusion, respectively.

Because each model compound has high hydrophilicity, lipophilic index $\mathrm{P}_{\mathrm{a}}$ of each model compound is very small. This might enable us to assume that each $\mathrm{P}_{\mathrm{a}}$ is approximately identical. Then, the right side of Eq. (3) can be transformed as a fixed number. As illustrated in Fig. 5, we examined the relationship between the $k_{a}$ and the reciprocal value of the square root of the molecular weight $(1 / \sqrt{\mathrm{Mw}})$ of the compounds. A linear relationship was observed between the $k_{a}$ and $1 / \sqrt{\mathrm{Mw}}$ of these compounds (correlation coefficient: $\mathrm{r}^{2}=$ 0.97), suggesting that these hydrophilic compounds with different molecular weights are absorbed from the rat kidney surface membrane via simple passive diffusion.

The molecular weight when the $k_{a}$ value was 0 (x-intercept) was extrapolated to be 130,890 from the plot in Fig. 5. We consider that the limit (so-called threshold value) of the molecular weight of the drug absorbed from the rat kidney surface is approximately 130,000, which is much larger than that restricting the movement of macromolecules from the peritoneum (Mw: ca. 50,000) reported by Flessner et al. [12] and Hirszel et al. [31]. Therefore, the pore size of the kidney surface membrane is likely to be larger compared to the general peritoneal membrane. In addition, significant differences were seen in the absorption rate and molecular weight limit, compared to the liver surface membrane (approximately 70,000) [17], implying that organ surface membranes are not uniform with respect to absorption characteristics, probably because of differences in the intercellular gaps and pores among the peritoneal organ surfaces. The basic information concerning 
difference in absorption characteristics among the peritoneal organs might be useful to examine the pharmacokinetics of a drug in the peritoneal cavity. A simple pharmacokinetic model such as spatially distributed model proposed by Dedrick and Flessner [32] could be applied to perform pharmacokinetic calculations by utilizing permeability area product of each organ surface.

In conclusion, we clarified the absorption mechanism such as dose and molecular weight dependence of drug absorption from the kidney surface in rats. Such information would help this new administration route to improve specific delivery of therapeutic agents to the diseased region in the unilateral kidney.

\section{Acknowledgements}

We wish to thank Masanori Kobayashi and Manabu Kamenosono for skilled technical assistance. This study was supported in part by a Grant-in-Aid for Scientific Research from the Ministry of Education, Culture, Sports, Science and Technology, Japan.

\section{References}

[1] S. Noda, S. Konno, J. Tanaka, M. Yamada, N. Yoshitake, Treatment of renal cell carcinoma with intra-arterial administration of SMANCS dissolved in Lipiodol, Anticancer Res. 10 (1990) 709-715.

[2] M. Kobayashi, K. Imai, S. Sugihara, H. Maeda, T. Konno, H. Yamanaka, Tumor-targeted chemotherapy with lipid contrast medium and macromolecular anticancer drug (SMANCS) for renal cell carcinoma, Urology 37 (1991) 288-294.

[3] T. Kato, R. Nemoto, H. Mori, M. Takahashi, Y. Tamakawa, Transcatheter arterial 
chemoembolization of renal cell carcinoma with microencapsulated mitomycin C, J. Urol. 125 (1981) 19-24.

[4] T. Kato, K. Sato, R. Sasaki, H. Kakinuma, M. Moriyama, Targeted cancer chemotherapy with arterial microcapsule chemoembolization: review of 1013 patients, Cancer Chemother. Pharmacol. 37 (1996) 289-296.

[5] D.J. Kerr, N. Willmott, J.H. McKillop, J. Cummings, H.J. Lewi, C.S. McArdle, Target organ disposition and plasma pharmacokinetics of doxorubicin incorporated into albumin microspheres after intrarenal arterial administration, Cancer 62 (1988) 878-883.

[6] C.S. McArdle, H. Lewi, D. Hansell, D.J. Kerr, J. McKillop, N. Willmott, Cytotoxicloaded albumin microspheres: a novel approach to regional chemotherapy, Br. J. Surg. 75 (1988) 132-134.

[7] S. Kawakami, T. Horimoto, K. Nishida, R. Hirayama, T. Mukai, M. Nakashima, H. Sasaki, T. Sakaeda, J. Nakamura, Kidney- and site-selective delivery of 5-fluorouracil utilizing the absorption on the kidney surface in rats, Biol. Pharm. Bull. 25 (2002) 928930.

[8] K. Nishida, N. Sato, H. Sasaki, J. Nakamura, Absorption of organic anions as model drugs following application to rat liver surface in-vivo, J. Pharm. Pharmacol. 46 (1994) 867-870.

[9] K. Nishida, N. Sato, H. Sasaki, J. Nakamura, Mechanism for drug absorption from ratliver surface membrane: effect of dose and transport inhibitors on the pharmacokinetics of phenol red, J. Pharm. Pharmacol. 47 (1995) 227-231.

[10]K. Nishida, N. Sato, H. Sasaki, J. Nakamura, Effect of albumin on the absorption of phenol red, bromphenol blue and bromosulphonphthalein as model drugs from the liver surface membrane in rats, Biol. Pharm. Bull. 18 (1995) 1548-1550.

[11]K. Nishida, N. Sato, Y. Nakakoga, T. Mukai, H. Sasaki, J. Nakamura, Effect of 
application volume and area on the absorption of phenol red, as a model drug, from the liver surface in rats, J. Pharm. Pharmacol. 49 (1997) 976-980.

[12] M.F. Flessner, R.L. Dedrick, J.S. Schultz, Exchange of macromolecules between peritoneal cavity and plasma, Am. J. Physiol. 248 (1985) H15-H25.

[13] J.K. Leypoldt, H.R. Parker, R.P. Frigon, L.W. Henderson, Molecular size dependence of peritoneal transport, J. Lab. Clin. Med. 110 (1987) 207-216.

[14] J.A. Nagy, K.T. Herzberg, E.M. Masse, G.P. Zientara, H.F. Dvorak, Exchange of macromolecules between plasma and peritoneal cavity in ascites tumor-bearing, normal, and serotonin-injected mice, Cancer Res. 49 (1989) 5448-5458.

[15]L.W. Seymour, R. Duncan, J. Strohalm, J. Kopecek, Effect of molecular weight (Mw) of $\mathrm{N}$-(2-hydroxypropyl)methacrylamide copolymers on body distribution and rate of excretion after subcutaneous, intraperitoneal, and intravenous administration to rats, J. Biomed. Mater. Res. 21 (1987) 1341-1358.

[16] Y. Yamamura, T. Santa, H. Kotaki, K. Uchino, Y. Sawada, T. Iga, Administration-route dependency of absorption of glycyrrhizin in rats: intraperitoneal administration dramatically enhanced bioavailability, Biol. Pharm. Bull. 18 (1995) 337-341.

[17]K. Nishida, N. Sato, H. Sasaki, J. Nakamura, Absorption characteristics of dextrans with different molecular weights from the liver surface membrane in rats: implications for targeting to the liver, J. Drug Target. 4 (1996) 141-150.

[18] M.F. Flessner, R.L. Dedrick, J.C. Reynolds, Bidirectional peritoneal transport of immunoglobulin in rats: compartmental kinetics, Am. J. Physiol. 262 (1992) F275-F287.

[19]L.W. Seymour, R. Duncan, V. Chytry, J. Strohalm, K. Ulbrich, J. Kopecek, Intraperitoneal and subcutaneous retention of a soluble polymeric drug-carrier bearing galactose, $\mathrm{J}$. Control. Rel. 16 (1991) 255-262.

[20]L.G. Hart, L.S. Schanker, The chemical forms in which phenol red is secreted into the bile 
of rats, Proc. Soc. Exp. Biol. Med. 123 (1966) 433-435.

[21]K. Takada, O. Narumiya, S. Muranishi, Biopharmaceutical study of the hepato-biliary transport of drugs. III. Binding characteristics of bromphenol blue and amaranth to the liver cytoplasmic Y and Z binding proteins in vitro, Chem. Pharm. Bull. 23 (1975) 729735.

[22]K.J. Baker, S.E. Bradley, Binding of sulfobromophthalein (BSP) sodium by plasma albumin. Its role in hepatic BSP extraction, J. Clin. Invest. 45 (1966) 281-287.

[23]K. Yamaoka, T. Nakagawa, T. Uno, Statistical moments in pharmacokinetics, J. Pharmacokinet. Biopharm. 6 (1978) 547-558.

[24]K. Yamaoka, Y. Tanigawara, T. Nakagawa, T. Uno, A pharmacokinetic analysis program (MULTI) for microcomputer, J. Pharmacobio-Dyn. 4 (1981) 879-885.

[25]K. Nishida, C. Tonegawa, S. Nakane, Y. Takakura, M. Hashida, H. Sezaki, Effect of electric charge on the hepatic uptake of macromolecules in the rat liver, Int. J. Pharm. 65 (1990) 7-17.

[26]K. Nishida, K. Mihara, T. Takino, S. Nakane, Y. Takakura, M. Hashida, H. Sezaki, Hepatic disposition characteristics of electrically charged macromolecules in rat in vivo and in the perfused liver, Pharm. Res. 8 (1991) 437-444.

[27]R. Mehvar, T.L. Shepard, Molecular-weight-dependent pharmacokinetics of fluoresceinlabeled dextrans in rats, J. Pharm. Sci. 81 (1992) 908-912.

[28] R. Mehvar, M.A. Robinson, J.M. Reynolds, Molecular weight dependent tissue accumulation of dextrans: in vivo studies in rats, J. Pharm. Sci. 83 (1994) 1495-1499.

[29] T. Koizumi, T. Arita, K. Kakemi, Absorption and excretion of drugs. XIX. Some pharmacokinetic aspects of absorption and excretion of sulfonamides. (1). Absorption from rat stomach, Chem. Pharm. Bull. 12 (1964) 413-420.

[30]T. Koizumi, T. Arita, K. Kakemi, Absorption and excretion of drugs. XX. Some 
pharmacokinetic aspects of absorption and excretion of sulfonamide. (2). Absorption from rat small intestine, Chem. Pharm. Bull. 12 (1964) 421-427.

[31]P. Hirszel, E.K. Chakrabarti, R.R. Bennett, J.F. Maher, Permselectivity of the peritoneum to neutral dextrans, Trans. Am. Soc. Artif. Intern. Organs 30 (1984) 625-629.

[32] R.L. Dedrick, M.F. Flessner, Pharmacokinetic problems in peritoneal drug administration: tissue penetration and surface exposure, J. Natl. Cancer Inst. 89 (1997) 480-487. 


\section{Table}

Table 1

Recovery (\% of dose) of free PSP and its metabolite $4 \mathrm{~h}$ after application to the kidney surface or i.v. administration in rats

\begin{tabular}{|c|c|c|c|c|c|c|c|}
\hline \multirow{2}{*}{$\begin{array}{l}\text { Dose } \\
\text { (mg) }\end{array}$} & \multirow{2}{*}{$\begin{array}{l}\text { Diffusion cell } \\
\text { (Free) }\end{array}$} & \multicolumn{3}{|c|}{ Bile } & \multicolumn{3}{|c|}{ Urine } \\
\hline & & Free & Metabolite & Total & Free & Metabolite & Total \\
\hline \multicolumn{8}{|c|}{ Kidney surface application } \\
\hline 0.5 & $\begin{array}{r}8.6 \\
\pm 1.0\end{array}$ & $\begin{array}{r}30.7 \\
\pm 3.2\end{array}$ & $\begin{array}{r}18.6 \\
\pm 3.7\end{array}$ & $\begin{array}{r}49.3 \\
\pm 1.8\end{array}$ & $\begin{array}{r}16.8 \\
\pm 2.0\end{array}$ & $\begin{array}{r}13.8 \\
\pm 1.6\end{array}$ & $\begin{array}{r}30.7 \\
\pm 2.8\end{array}$ \\
\hline 1 & $\begin{array}{r}3.6 \\
\pm 0.4\end{array}$ & $\begin{array}{r}34.1 \\
\pm 2.7\end{array}$ & $\begin{array}{r}16.0 \\
\pm 2.3\end{array}$ & $\begin{array}{r}50.1 \\
\pm 3.1\end{array}$ & $\begin{array}{r}13.6 \\
\pm 3.7\end{array}$ & $\begin{array}{r}11.9 \\
\pm 2.9\end{array}$ & $\begin{array}{r}25.5 \\
\pm 4.1\end{array}$ \\
\hline 1.5 & $\begin{array}{r}2.3 \\
\pm 0.6\end{array}$ & $\begin{array}{r}33.1 \\
\pm 3.9\end{array}$ & $\begin{array}{r}20.2 \\
\pm 3.1\end{array}$ & $\begin{array}{r}53.3 \\
\pm 6.3\end{array}$ & $\begin{array}{r}16.8 \\
\pm 6.4\end{array}$ & $\begin{array}{r}8.6 \\
\pm 1.5\end{array}$ & $\begin{array}{r}25.4 \\
\pm 7.6\end{array}$ \\
\hline \multicolumn{8}{|c|}{ I.v. administration } \\
\hline 1 & - & $\begin{array}{r}28.8 \\
\pm 3.5\end{array}$ & $\begin{array}{r}14.4 \\
\pm 1.5\end{array}$ & $\begin{array}{r}43.2 \\
\pm 2.1\end{array}$ & $\begin{array}{r}23.4 \\
\pm 2.8\end{array}$ & $\begin{array}{r}4.1 \\
\pm 0.8\end{array}$ & $\begin{array}{r}27.5 \\
\pm 3.5\end{array}$ \\
\hline
\end{tabular}

Each value is the mean \pm S.E. of four experiments. 
Table 2

Moment parameters of free PSP after application to the kidney surface or i.v. administration in rats

\begin{tabular}{cccc}
\hline Dose $(\mathrm{mg})$ & $\mathrm{AUC}_{\mathrm{p}}(\mu \mathrm{g} \cdot \mathrm{min} / \mathrm{ml})$ & $\mathrm{MRT}_{\mathrm{p}}(\mathrm{min})$ & $\mathrm{MAT}(\mathrm{min})$ \\
\hline \multicolumn{2}{l}{ Kidney surface application } & & \\
0.5 & 535 & 170 & 46.2 \\
& \pm 119 & \pm 27 & \pm 27.1 \\
1 & 1097 & 176 & 52.4 \\
& \pm 166 & \pm 44 & \pm 43.9 \\
1.5 & 1781 & 198 & 74.6 \\
& \pm 198 & \pm 21 & \pm 20.5 \\
I.v. administration & & & \\
1 & 955 & 124 & \\
\hline
\end{tabular}

Each value is the mean \pm S.E. of four experiments. 
Table 3

Recovery (\% of dose) of the compounds with different molecular weights 4 or $6 \mathrm{~h}$ after application to the rat kidney surface at a dose of $1 \mathrm{mg}$

\begin{tabular}{|c|c|c|c|c|c|}
\hline Compound & $\mathrm{Mw}$ & Time (h) & Diffusion cell & Bile & Urine \\
\hline PSP & 354 & 4 & $\begin{array}{r}3.6 \\
\pm 0.4\end{array}$ & $\begin{array}{c}50.1^{\mathrm{a}} \\
\pm 3.1\end{array}$ & $\begin{array}{r}25.5^{\mathrm{a}} \\
\pm 4.1\end{array}$ \\
\hline ВРВ & 670 & 4 & $\begin{array}{r}10.5 \\
\pm 0.8\end{array}$ & $\begin{array}{r}55.4 \\
\pm 2.3\end{array}$ & $\begin{array}{r}2.4 \\
\pm 1.2\end{array}$ \\
\hline BSP & 838 & 4 & $\begin{array}{r}19.0 \\
\pm 4.2\end{array}$ & $\begin{array}{r}61.9 \\
\pm 3.7\end{array}$ & $\begin{array}{r}2.5 \\
\pm 0.7\end{array}$ \\
\hline FD-4 & 4,400 & 6 & $\begin{array}{r}23.9 \\
\pm 1.2\end{array}$ & N.D. & $\begin{array}{r}67.3 \\
\pm 3.5\end{array}$ \\
\hline FD-10 & 11,000 & 6 & $\begin{array}{r}45.6 \\
\pm 1.6\end{array}$ & N.D. & $\begin{array}{r}48.5 \\
\pm 2.5\end{array}$ \\
\hline FD-40 & 40,500 & 6 & $\begin{array}{r}88.5 \\
\pm 0.7\end{array}$ & N.D. & $\begin{array}{r}5.5 \\
\pm 0.6\end{array}$ \\
\hline FD-70 & 69,000 & 6 & $\begin{array}{r}96.1 \\
\pm 1.0\end{array}$ & N.D. & $\begin{array}{r}1.6 \\
\pm 0.1\end{array}$ \\
\hline
\end{tabular}

Each value is the mean \pm S.E. of four experiments.

N.D.: not detected.

a) Total recovery of free PSP and its metabolite. 


\section{Figure captions}

Fig. 1. Semi-log plot of time course of free PSP amount remaining in the diffusion cell after application to the rat kidney surface at a dose of $1 \mathrm{mg}$. Each point represents the mean \pm S.E. of at least four experiments.

Fig. 2. Plasma concentration profiles of free PSP after application to the rat kidney surface at doses of $0.5(\mathbf{\Delta}), 1(\bigcirc)$ and $1.5 \mathrm{mg}(\boldsymbol{O})$. Each point represents the mean \pm S.E. of four experiments. Curves show the simulated function based on the pharmacokinetic parameters by two-compartment model.

Fig. 3. Plasma concentration profiles of FD-4 ( $)$ ), FD-10 ( $\bigcirc)$, FD-40 ( $\mathbf{\Delta})$ and FD-70 $(\triangle)$ after application to the rat kidney surface at a dose of $1 \mathrm{mg}$. Each point represents the mean \pm S.E. of four experiments.

Fig. 4. First-order absorption rate constant $k_{a}$ of PSP, BPB, BSP and FDs (FD-4, FD-10, FD-40, FD-70) after application to the rat kidney surface at a dose of $1 \mathrm{mg}$. Each column represents the mean + S.E. of four experiments. $\quad k_{a}$ was calculated from the amount remaining in the diffusion cell at 4 or $6 \mathrm{~h}$.

Fig. 5. Relationship between the molecular weight of the compounds and first-order absorption rate constant $k_{a}$ after application to the rat kidney surface. Each point represents the mean \pm S.E. of four experiments. $\quad$ 1: PSP, 2: BPB, 3: BSP, 4: FD-4, 5: FD-10, 6: FD-40, 7: FD-70. 